\title{
TRABALHO E EDUCAÇÃO INFANTIL EM MARX E ENGELS
}

\author{
José Claudinei Lombardi ${ }^{1}$ \\ FE / HISTEDBR / Unicamp
}

\begin{abstract}
RESUMO:
A problemática do trabalho e da educação infantil não tem sido objeto de minhas pesquisas e preocupações. Entretando acabei me debruçando sobre o tema em minha recente tese de livre-docência, motivado pelas críticas recebidas por Marx e Engels sobre o modo como trataram o trabalho infantil. A crítica recebida pelos fundadores do marxismo era quanto a defesa que fizeram do trabalho infantil e da articulação do trabalho com a escolarização. Fui adentrando no tema, buscando entendê-lo historicamente, buscando seguir um duplo e contraditório fio condutor: por um lado buscando verificar historicamente a contibuidade do uso do trabalho infantil, como uma característica da exploração capitalista, e que chega com significância ainda aos dias atuais; acabei buscando informações que demonstravam que ainda hoje pode-se constatar o uso do trabalho infantil, nos mais diferentes setores da economia e nos mais diferentes países; por outro lado, tendo em vista que o trabalho é característica fundamental para a existência do homem, sendo alçada inclusive como um princípio dos principios fundamentais da educação, na perspectiva marxista, busquei entender mais profundamentamente como Marx e Engels trataram do tema em suas obras. Essa é a problemática que buscarei tratar no presente artigo que, para efeitos expositivos, encontra-se dividido em quatro partes articuladas, sucessivamente buscando entender como contemporaneamente coloca-se a questão do trabalho infantil, em seguida situando a crítica feita a Marx e Engels e, depois, nas duas outras partes, adentrando na discussão feita por esses dois clássicos sobre esse tema.
\end{abstract}

Palavras-Chave: Trabalho infantil; educação da criança; Marx e Engels e a Infância

\section{CHILDISH LABOR AND EDUCATION IN MARX AND ENGELS}

\begin{abstract}
:
The problem about childish labor and education hasn't been the subject of my research and concerns. However, i just did touch upon the theme in my recent thesis of free teaching, which was motivated by criticism of Marx and Engels about the way they treated the child labor. The criticism by the founders of Marxism was about the defense that made child labor and joint work with schooling. I was entering on the subject, trying to understand it historically, searching to follow a double and contradictory thread: first trying to verify the historical continuity of child labor uses, as characteristic of capitalist exploitation, and that still comes with significance to today; just looking for information showing that even today one can see the use of child labor, in many different sectors of the economy and in different countries; on the other hand, considering that the work is an essential feature for the man's existence, being even lifted as one of the fundamental education principles in the Marxist perspective, I will try to understand more deep inside as Marx and Engels addressed the issue in their works. That is the problem which seeks to address in this article that for expository purposes, is divided into four parts articulated successively seeking to understand how simultaneously raises the issue of child labor, then placing the critique of Marx and Engels Then the two other parties entering into the discussion made by these two classics on this theme.
\end{abstract}

Keywords: Child labor, child's education; Marx and Engels and Childhood 


\section{O trabalho infantil na contemporaneidade}

Apesar da busca por amparo e proteção legal contra os abusos do uso do trabalho infantil, desde o século XIX, tem-se que reconhecer que a exploração do trabalho infantil continuou a ser uma prática usual, em escala internacional, a ponto da Organização Internacional do Trabalho (OIT) buscar seu disciplinamento. Assim, a Convenção $\mathrm{n}^{\circ} 138$ da OIT, de 1973, em seu artigo $2^{\circ}$, item 3, fixa a idade de 16 anos como idade mínima recomendada para o trabalho em geral. Entretanto, no caso dos países considerados muito pobres, admite-se que seja fixada uma idade mínima de 14 anos para o trabalho. MAS a mesma Convenção admite o trabalho leve na faixa etária entre os 13 e os 15 anos, registrando que o mesmo não deve prejudicar a saúde ou o desenvolvimento do jovem, a ida deste à escola ou sua participação em orientação vocacional ou programas de treino.

O uso do trabalho infantil continua, portanto, a ser uma prática usual na atualidade, sendo motivo de preocupação da UNICEF (um Fundo das Nações Unidas específico para a Infância), criado em 1946 como uma agência da ONU (Organização das Nações Unidas) para promover a defesa dos direitos das crianças, prestar ajuda para o atendimento de suas necessidades básicas e contribuir para o seu pleno desenvolvimento. Para esta agência o trabalho infantil é definido como toda forma de trabalho abaixo dos 12 anos de idade, em quaisquer atividades econômicas; qualquer trabalho entre 12 e 14 anos que não seja trabalho leve; todo o tipo de trabalho abaixo dos 18 anos enquadrado pela OIT nas "piores formas de trabalho infantil". A Convenção $\mathrm{n}^{\circ} 182$ da OIT, de 1999, classifica como as piores formas de trabalho infantil: o trabalho escravo ou semi-escravo (o que é realizado em condição análoga à da escravidão), o trabalho decorrente da venda e tráfico de menores, a escravidão por dívida, o uso de crianças ou adolescentes em conflitos armados, a prostituição e a pornografia de menores; o uso de menores para atividades ilícitas, tais como a produção e o tráfico de drogas; e o trabalho que possa prejudicar a saúde, segurança ou moralidade do menor.

No Brasil, seguindo uma trajetória de sucessivas legislações, a Constituição Federal de 1988 , em seu art. $7^{\circ}$, XXXIII) estabeleceu o inicio do trabalho, em geral, a partir dos 16 anos, exceto nos casos de trabalho noturno, perigoso ou insalubre, em que a idade mínima é 18 anos; como ocorre historicamente, também na atualidade estabelecem-se exceções, admitindo-se o trabalho a partir dos 14 anos (art. 227, § $3^{\circ}$, I), mas somente na condição de aprendiz (art. $7^{\circ}, \mathrm{XXXIII).} \mathrm{A} \mathrm{legislação} \mathrm{brasileira} \mathrm{coloca} \mathrm{uma} \mathrm{ênfase} \mathrm{especial} \mathrm{para} \mathrm{as}$ formas mais nocivas de trabalho infantil, como o trabalho infantil escravo, a jornada exaustiva ou condições degradantes de trabalho (artigo 149 do Código Penal), com a agravante de se tratar de criança ou adolescente $\left(\S 2^{\circ}\right.$, item I), agravante esta introduzida pela lei 10.803, de 11 de Dezembro de 2003, aumentando a pena em uma metade. A legislação brasileira também trata, de modo especial, outros aspectos sobre a infância, como: maus-tratos, com perigo a vida ou a saúde de criança ou adolescente, sujeitando-a a trabalho excessivo ou inadequado (artigo 136 do Código Penal); caso o adolescente seja menor de 14 anos, há a agravante do $\S 3^{\circ}$, introduzida pelo ECA (lei 8.069/90), que aumenta a pena em mais um terço; exploração da prostituição de menores, crime considerado pela OIT como uma das piores formas de trabalho infantil, estando previsto no artigo 244-A do Estatuto da Criança e do Adolescente (ECA, instituído pela Lei 8.069 no dia 13 de julho de 1990); pornografia de menores, crime previsto nos artigos 240 e 241 do ECA; venda ou tráfico de menores, crime também previsto no artigo 239 do ECA.

Essa caracterização e disposição legal, tanto a internacional como a brasileira, possibilita inferirmos que, não somente o trabalho infantil não somente tem continuidade, até os dias de hoje, como o capital mantém as mais horrendas formas de trabalho, inclusive 
o infantil. Mas a inferência torna-se demonstração pelo acesso aos dados e estatísticas oficiais sobre o trabalho infantil na atualidade e que trazem uma visão panorâmica da importância que a exploração infantil ainda tem para o capital, pois este amplia sua acumulação, mantendo na miséria milhões de trabalhadores. Em decorrência dessa situação, dados constantes do site da Unicef ${ }^{2}$ informam que milhões de crianças trabalham para ajudar suas famílias: os dados referentes ao período de 1999-2008 informam que uma em cada seis crianças de 5 a 14 anos de idade, cerca de $16 \%$ de todas as crianças nessa faixa etária, está envolvida no trabalho infantil nos países em desenvolvimento; para os países menos desenvolvidos, cerca de $30 \%$ de todas as crianças estão envolvidas em trabalho infantil, chegando a $35 \%$ as crianças submetidas a trabalho na África. Os dados constam do gráfico que segue e que mantemos como divulgado no site:

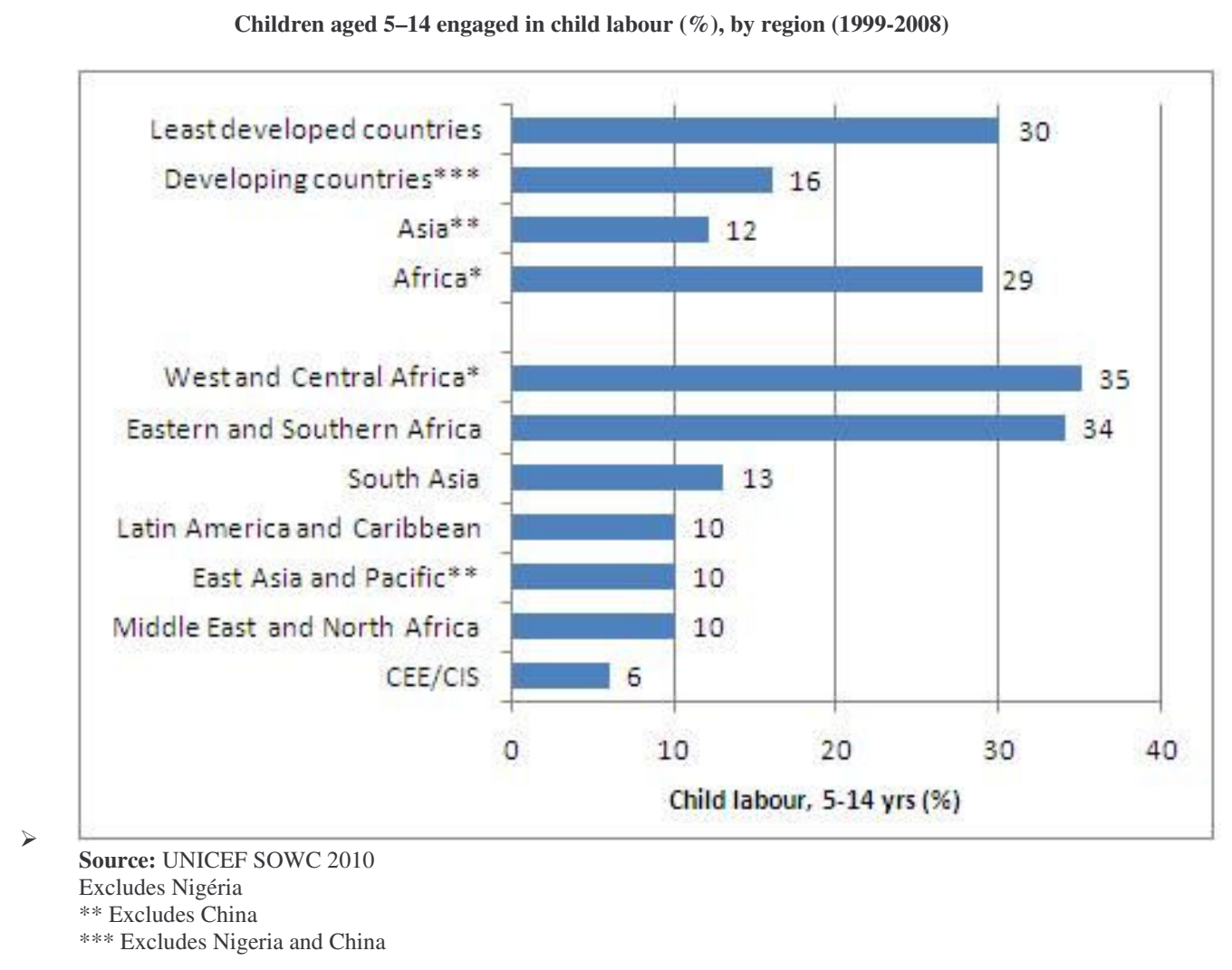

Ao informar que cerca de 1 em cada 3 crianças de 5-14 da África trabalham, concomitantemente a baixa incidência de trabalho infantil entre os países desenvolvidos, onde apenas 1 em 20 na Europa Central e Comunidade de Estados Independentes (CEE / CIS região). Outro gráfico traz outras informações: que as crianças que vivem em famílias mais pobres e nas zonas rurais são mais submetidas ao trabalho infantil; que os meninos são mais requeridos para o trabalho infantil que meninas, mas estas são mais sobrecarregadas com as tarefas domésticas. A distribuição sexual do trabalho infantil encontra-se assim registrada no site da UNICEF: 
Children aged 5-14 engaged in child labour (\%), by gender (1999-2008)

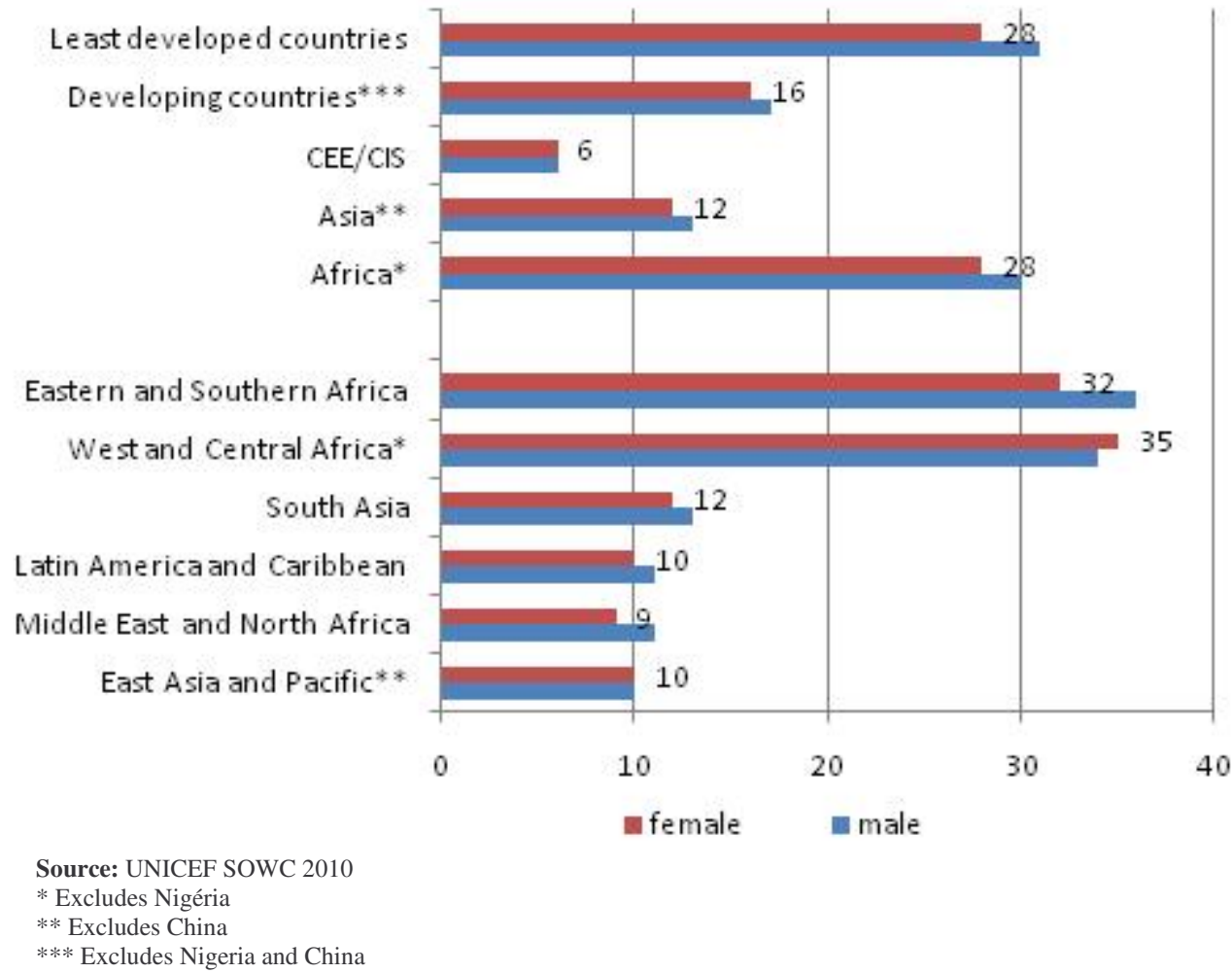

Buscando a base de dados do UNICEF é possível encontrarmos estatísticas da situação infantil no Brasil, bem como a alarmante situação apresentada em alguns países, notadamente no continente africano. Ainda são inúmeros os países em que $50 \%$ de crianças de 5 a 14 anos trabalham arduamente, como é o caso do Chade, da Etiópia, da Nigéria, de Serra Leoa e da Somália. Somente para ilustração, buscamos desmembrar os dados apresentados na tabela, reconstituindo como segue:

Child labour, 5-14 years (\%),1999-2008

\begin{tabular}{|c|c|c|c|c|c|c|}
\hline Countries and territories & \multicolumn{2}{|c|}{ Total } & \multicolumn{2}{|c|}{ Male } & \multicolumn{2}{|c|}{ Female } \\
\hline Belize & 40 & & 39 & & 42 & \\
\hline Benin & 46 & & 47 & & 45 & \\
\hline Brazil & 6 & $\mathrm{Y}$ & 7 & $\mathrm{Y}$ & 4 & $\mathrm{Y}$ \\
\hline Burkina Faso & 47 & $\mathrm{Y}$ & 46 & $\mathrm{Y}$ & 48 & $\mathrm{Y}$ \\
\hline Cambodia & 45 & $\mathrm{Y}$ & 45 & $\mathrm{Y}$ & 45 & $\mathrm{Y}$ \\
\hline Central African Republic & 47 & & 44 & & 49 & \\
\hline Chad & 53 & & 54 & & 51 & \\
\hline Ethiopia & 53 & & 59 & & 46 & \\
\hline Niger & 43 & & 43 & & 43 & \\
\hline Sierra Leone & 48 & & 49 & & 48 & \\
\hline Somalia & 49 & & 45 & & 54 & \\
\hline
\end{tabular}


SUMMARY INDICATORS

\begin{tabular}{|l|r|l|r|l|r|l|}
\hline Africa & 29 & $\mathrm{~N}$ & 30 & $\mathrm{~N}$ & 28 & $\mathrm{~N}$ \\
\hline Sub-Saharan Africa & 33 & $\mathrm{n}$ & 34 & $\mathrm{~N}$ & 32 & $\mathrm{~N}$ \\
\hline \multicolumn{1}{|c|}{ Eastern and Southern Africa } & 34 & & 36 & & 32 & \\
\hline West and Central Africa & 35 & $\mathrm{n}$ & 34 & $\mathrm{~N}$ & 35 & $\mathrm{~N}$ \\
\hline Middle East and North Africa & 10 & 11 & & 9 & \\
\hline Asia & 12 & $* *$ & 13 & $* *$ & 12 & $* *$ \\
\hline South Asia & 13 & & 13 & & 12 & \\
\hline East Asia and Pacific & 10 & $* *$ & 10 & $* *$ & 10 & $* *$ \\
\hline Latin America and Caribbean & 10 & & 11 & & 10 & \\
\hline CEE/CIS & 6 & & 6 & & 6 & \\
\hline Industrialized countries & - & & - & & - & \\
\hline Developing countries & 16 & $* * *$ & 17 & $* * *$ & 16 & $* * *$ \\
\hline Least developed countries & 30 & & 31 & & 28 & \\
\hline
\end{tabular}

Fonte: http://www.childinfo.org/labour_countrydata.php

Os dados apresentados são expressivos. Ao registrar o envolvimento dessas crianças com o trabalho, o UNICEF é taxativo na afirmativa de que se trata "de drenagem de alegria e de esmagamento do direito ao desenvolvimento físico e mental normal", certamente com interferência na educação dessas crianças. Dispondo do conjunto de dados, a matéria traz uma representação de um mapa mundi com a distribuição percentual do trabalho infantil pelos países e continentes, como segue:

Percentage of children aged 5-14 years engaged in child labour (2003-2008)
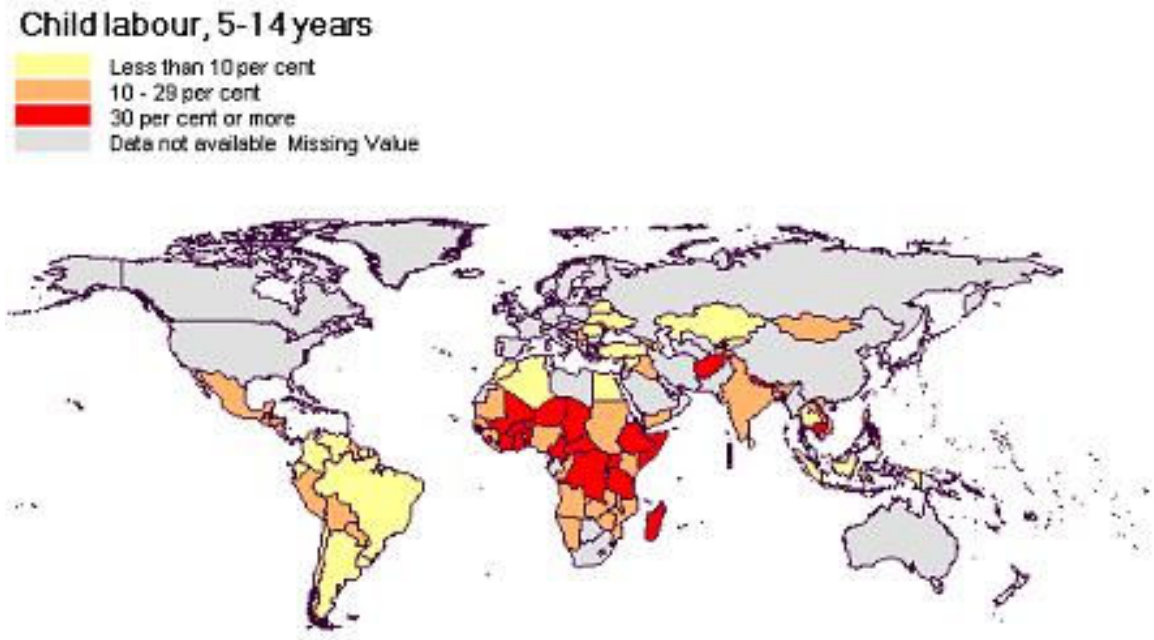

Source: UNICEF global databases, 2009.

Não há condições de grandes aprofundamentos sobre o assunto, mas vale registrar que Ana Lúcia Kassouf, em artigo intitulado "O que conhecemos sobre o trabalho infantil?", torna esses dados um pouco mais visíveis, quantificando e qualificando os dados disponíveis sobre trabalho infantil no Brasil. Observa ela que ainda que o trabalho infantil esteja diminuindo, há um grande número de crianças trabalhando, conforme dados da 
Organização Internacional do Trabalho que estimou, em 2000, a existência de 211 milhões de crianças entre cinco e 14 anos trabalhando, com as maiores porcentagens na Ásia, na África e na América Latina. Com relação ao Brasil, recorrendo a dados da PNAD de 2005, existem quase três milhões de crianças e jovens de cinco a 15 anos trabalhando $(7,8 \%$ do total nessa faixa etária), tendo ocorrido um declínio acentuado, principalmente, a partir da metade da década de 1990. Os dados de 1992, por exemplo, indicavam a existência de quase cinco milhões e meio de crianças trabalhando (14,6\% da população entre cinco e 15 anos). Tal qual os dados mundiais, a autora aponta que a proporção de meninos trabalhando é maior que a de meninas, exceto no emprego doméstico. Também a porcentagem de trabalho infantil nas áreas rurais é bem mais elevada do que nas áreas urbanas do Brasil (Kassouf, 2007, s.d.).

Kassouf afirma que os dados sempre são passíveis de sub ou superestimações, exemplificando essas possibilidades a partir dos dados do referido PNAD, que haviam 2.934.724 crianças, entre 5 e 15 anos, trabalhando uma hora ou mais na semana anterior à pesquisa, não incluindo as crianças procurando emprego ou exercendo atividades domésticas. Entretanto, considerando apenas aquelas exercendo atividades por 14 horas ou mais na semana, o número cai para 1.897.877; mas contabilizando-se as crianças que trabalham por uma hora ou mais na semana, em qualquer tipo trabalho, esse número passa para 3.495.870; definindo-se o trabalho como aquele exercido por mais de 13 horas por semana em atividades domésticas ou não, sem dupla contagem, teríamos 4.713.439 menores, enquanto 18.059.327 trabalham ou exercem atividades domésticas por 1 hora ou mais na semana. Esses dados foram organizados na Tabela 1 pela autora e, somente para ilustração, encontra-se na sequência:

Tabela 1_Número e porcentagem de crianças trabalhando

\begin{tabular}{|c|c|c|}
\hline Crianças de 5 a 15 anos & Número & $\%$ \\
\hline Trabalhando 14 horas ou mais na semana & 1.897 .877 & 5,0 \\
\hline Trabalhando 1 hora ou mais na semana & 2.934 .724 & 7,8 \\
\hline $\begin{array}{l}\text { Trabalhando } 1 \text { hora ou mais na semana em qualquer trabalho } \\
\text { que tenha tido no ano anterior à pesquisa }\end{array}$ & 3.495 .870 & 9,3 \\
\hline Trabalhando no ano e procurando emprego & 3.625 .490 & 9,6 \\
\hline $\begin{array}{l}\text { Trabalhando ou exercendo atividades domésticas por } 14 \text { horas } \\
\text { ou mais na semana }\end{array}$ & 4.713 .439 & 12,5 \\
\hline $\begin{array}{l}\text { Trabalhando ou exercendo atividades domésticas por } 1 \text { hora } \\
\text { ou mais na semana }\end{array}$ & 18.059 .327 & 48,0 \\
\hline
\end{tabular}

Fonte: PNAD (2005).

A principal relativização dos dados, porém, não é somente decorrência da sub ou superestimação, mas do fato de que o trabalho das crianças e adolescentes situam-se no âmbito da pseudo informalidade, principalmente inseridas em atividades ilícitas (como tráfico de drogas, prostituição, etc.).

Mas o que ocorreu que somente muito recentemente a questão da exploração do trabalho infantil voltou à tona? A resposta mais fidedigna encontrei no já referido artigo de Ana Lúcia Kassouf, onde a autora registra que após o interesse pelo tema na segunda metade do século XIX e início do XX, por autores como Karl Marx, Alfred Marshall e 
Arthur Pigou, entre outros, o interesse acadêmico pela redução do trabalho infantil é muito recente, demarcando que somente por volta de 1995 ocorreu o ressurgimento de "pesquisas e análises econômicas sobre o assunto" (Kassouf, 2007, s.d.). Esse interesse acadêmico ocorreu como um desdobramento da adoção de políticas internacionais voltadas à eliminação das piores formas do trabalho infantil, como destaca a autora:

O recente interesse acadêmico coincide com a elevação do número de políticas nacionais e internacionais voltadas para a redução do trabalho infantil. As principais convenções internacionais englobam: a das Nações Unidas para o Direito das Crianças, em 1989, a Convenção 182 da OIT para eliminação das piores formas de trabalho infantil, em 1999, e a Declaração do Milênio com ênfase na redução da pobreza e na educação universal, estabelecida em 2000. (Idem, ibidem)

Atualmente análises sobre as causas, consequências e soluções para o trabalho infantil estão facilitadas pela disponibilidade de grande quantidade de dados, bem como pelas facilidades de cruzamento das informações, graças aos recursos computacionais disponíveis. No Brasil a principal fonte de informações para a análise sobre o trabalho infantil é a Pesquisa Nacional por Amostra de Domicílios (PNAD), complementada por informações da Pesquisa Mensal de Emprego (PME), por dados do Sistema Nacional de Avaliação da Educação Básica (SAEB) e outras.

A amplitude quantitativa e qualitativa do trabalho infantil no Brasil pode ser aquilatada através do SITI (o Sistema de Informações sobre focos de Trabalho Infantil), alimentado pelo Ministério do Trabalho e Emprego, cobrindo praticamente todos os Estados do Brasil e no qual são registrados os focos denunciados, a atividade e o tipo de atividade econômica em que se localizam e as ações (ou providências) tomadas. A visualização das informações possibilita identificar que a exploração do trabalho infantil continua a ter forte presença na economia brasileira, inclusive nos Estados economicamente mais desenvolvidos da federação, abarcando praticamente todos os setores da atividade econômica. ${ }^{3}$

\section{O equivocado prognóstico de Marx}

Apesar do trabalho infantil chegar à atualidade, desvelando que trata-se de uma exploração de trabalho característica do modo capitalista de produção, inúmeros autores apontam um suposto equívoco de Marx ao analisar a importância da utilização do trabalho infantil pela indústria moderna, enfatizando que Marx expressou uma opinião sobre o trabalho infantil na indústria que foi infirmada pela evolução histórica. Para Maria Alice Nogueira (1990, p. 29-31), Marx acreditava que o uso da força de trabalho infantil "tinha um caráter definitivo" ou que expressava uma tendência irreversível, baseado no pressuposto de que "a indústria capitalista não mais poderia prescindir dessa categoria de trabalhadores", decorrência da necessidade que tinha de braços para alimentar o processo de acumulação do capital (Idem, p. 29). Nogueira destaca dois textos, em dois diferentes momentos da obra marxiana, em que essa tese fica manifesta: nas Instruções aos Delegados do Primeiro Congresso da Associação Internacional dos Trabalhadores (AIT), de 1866; e na crítica ao programa do Partido Operário Alemão, de 1875.

Nas instruções dirigidas aos delegados do Conselho Central ao primeiro congresso da Associação Internacional dos Trabalhadores (AIT) (1866), no item "Trabalho dos Adolescentes e Crianças dos Dois Sexos", encontra-se registrado o que segue: 


\begin{abstract}
Consideramos a tendência da indústria moderna para levar as crianças e jovens de ambos os sexos a cooperarem no grande trabalho da produção social como uma tendência progressiva, sã e legítima, embora sob o capital tenha sido distorcida numa abominação. Num estado racional da sociedade qualquer criança que seja, desde a idade dos 9 anos, deve tornar-se trabalhador produtivo da mesma maneira que todo o adulto saudável não deveria ser eximido da lei geral da natureza: Trabalhar para comer, e trabalhar não só com o cérebro mas também com as mãos. (MARX, K. Instruções para os Delegados do Conselho Geral Provisório. As Diferentes Questões. Agosto de 1866).
\end{abstract}

Deixando de lado, por absoluta falta de espaço, o entendimento de Marx e Engels quanto à importância do trabalho como uma categoria ontológica, isto é, como uma dimensão fundamental para o entendimento do homem e da necessária e permanente produção de suas condições de existência, pressupõe-se que Marx estava preocupado, por um lado, em fazer um prognóstico quanto a manutenção da utilização do trabalho infantil na indústria, por outro, em emitir um juízo de valor ao considerar o trabalho infantil uma medida social salutar, desde que exercida sob condições aceitáveis, que não coloquem em risco o desenvolvimento físico e intelectual da criança.

O outro texto referido é a Crítica ao programa de Gotha, de 1875, no comentário ao item em que se reivindicava a "Interdição do trabalho das crianças, bem como do trabalho das mulheres que causa prejuízo à saúde e à moralidade". Em suas notas, Marx assim posicionou-se:

A "proibição geral" do trabalho infantil é incompatível com a existência da grande indústria e, portanto, um piedoso desejo e nada mais. Por em prática esta proibição - supondo-a factível -= seria reacionário, uma vez que, regulamentada severamente a jornada de trabalho segundo as diferentes idades e aplicando as demais medidas preventivas para a proteção das crianças, a combinação do trabalho produtivo com o ensino, desde uma tenra idade, é um dos mais poderosos meios de transformação da sociedade atual. (MARX, Crítica ao Programa de Gotha. p. 224)

Novamente, perdendo de perspectiva o caráter datado da obra marxiana e seu entendimento político quanto ao trabalho e a instrução politécnica, Nogueira encontra nesse trecho a idéia de impossibilidade de exclusão da criança do universo da fábrica e entende que Marx "aproveita a ocasião" e reafirma "um princípio que ele lutara outrora por inserir na plataforma do movimento comunista", qual seja: de que "não se trata de suprimir o trabalho das crianças, mas sim de lhes garantir condições dignas de trabalho e, sobretudo, de lhes assegurar o acesso aos estudos teóricos em articulação com a sua prática profissional, meio privilegiado de luta contra a divisão do trabalho estabelecida em nossas sociedades" (Nogueira, 1990, p. 30).

A autora não está interessada em discutir a idéia de articulação entre estudo e trabalho, mas sim a suposta previsão marxiana e o desmentido histórico que fez com que a fábrica sobrevivesse à abolição do trabalho infantil. Nogueira reconhece, entretanto, que a tendência a dispensar o uso do trabalho da criança começou "a se esboçar após o período em que Marx desenvolveu as suas pesquisas" (Idem, pp. 30-31), e que decorreu da combinação de vários fatores: do progresso tecnológico, do combate à exploração do trabalho infantil e feminino e que resultou em medidas de proteção à infância, da mobilização de outras fontes de força de trabalho, como a imigração de trabalhadores. Disso conclui que, do desenvolvimento de condições técnicas e sociais da produção e da 
resistência da classe operária, a criança pode ser liberada do mundo da produção nos países do "centro" do capitalismo, ainda que nos países "periféricos" (como observa a autora na nota de rodapé 12 , p. 31), a mão-de-obra infantil continue a ser explorada, em condições análogas às descritas por Marx e Engels.

Sobre o assunto, conclui que "Marx foi provavelmente vítima de seu contexto sócio-econômico" - a primeira fase da industrialização - que aparentava que a indústria, "com seu enorme apetite de braços... não mais poderia renunciar à mão-de-obra infantil" (Idem, ibidem).

\section{A difusão do uso capitalista do trabalho da criança}

Como é sabido, a problemática da infância - assim como outras - não foi tema central em Marx ou Engels, entretanto ocupa posição de destaque para realçar a violenta exploração do trabalho pela moderna indústria capitalista. Neste item analisarei como Marx e Engels trataram o trabalho infantil e a problemática da educação das crianças, num contexto histórico que se abre a partir do fim do século XVIII na Inglaterra, geralmente denominado como "Revolução Industrial", ou "Primeira Revolução Industrial”, e que foi marcado pela utilização da máquina a vapor, do coque, com colossal desenvolvimento da indústria têxtil e uma estrondosa transformação nos transportes, com construção de extensas redes ferroviárias e de frotas de navio impulsionado a vapor, etc. Para demonstrar o que isso implicava aos trabalhadores, um dos focos tratados por Marx, como se viu, foi a ampliação do uso do trabalho das mulheres e do trabalho infantil nas fábricas nascentes.

Como se sabe, a Revolução Industrial representou uma série de transformações técnicas e sociais da produção e que marcaram a transição de uma produção de caráter artesanal, para a produção industrial moderna. Nessa transformação, o modo de trabalho, antes baseado principalmente na habilidade e destreza do trabalhador, foi gradativamente substituído por uma nova organização da produção, assentado num sistema de máquinas e que impôs à produção um ritmo e uma regularidade de produção independente do trabalhador, garantindo rapidez, precisão, regularidade, infatigabilidade.

Nesse processo de transformação, as fontes tradicionais de energia (força humana ou animal), cederam lugar ao uso de forças controláveis, como a energia hidráulica e, principalmente, o vapor, dotando a produção de crescente independência em relação aos acasos da natureza e em fator de elevação da produtividade. Essas transformações técnicas foram acompanhadas por transformações sociais mais amplas, devendo-se assinalar as transformações que se processaram na organização do trabalho, com a emergência do sistema fabril, a concentração de trabalhadores assalariados num mesmo teto, organizados segundo uma disciplina e vigilância instituída do exterior.

Além de registrar as transformações mais gerais da produção, o olhar de Marx e Engels direcionou-se para o registro da deterioração das condições de trabalho, da extensão da jornada e da intensificação do ritmo de trabalho, da redução dos salários e na conseqüente utilização intensiva da força de trabalho de mulheres e crianças. Não se pode esquecer que, para além da esfera produtiva, a Revolução Industrial constitui-se num amplo movimento que transformou praticamente todos os setores da vida social, das organizações e instituições sociais e políticas às mentalidades.

A história social assinala duas dessas principais transformações: o fenômeno da urbanização, por um lado, caracterizada pela reunião de grandes contingentes populacionais nas cidades, que passaram a concentrar as diferentes atividades organizativas da sociedade, como as produtivas, administrativas, intelectuais e outras; e, de outro lado, a constituição de uma classe operária - o proletariado - também composto por 
mulheres e crianças, decorrência da sub-remuneração dos trabalhadores masculinos adultos. Mas o trabalho infantil não foi invenção capitalista, pois seu uso é anterior à industrialização e já existia em épocas anteriores, como registram vários estudos historiográficos, assim sintetizados por Maria Alice Nogueira:

Seria [...] errôneo supor que o trabalho infantil data do século XIX e que foi a Revolução Industrial a responsável por ele, pois, em épocas anteriores, já se fazia uso da criança, embora sob outras formas. No meio rural, geralmente no quadro da família, a criança se ocupava de certas tarefas como, por exemplo, respigar e capinar o terreno, revolver o feno ou, mais comumente, guiar o rebanho [...] Já mais citadina, a oficina do artesão também empregava - como se sabe - o aprendiz, ao lado do oficial, sob a orientação do mestre. Isso sem falar no papel desempenhado pela criança nas famílias que viviam do trabalho domiciliar. Mas, se a indústria não foi a causadora do fenômeno, ela não é menos responsável por sua profunda transformação: a difusão em larga escala do trabalho infantil e, sobretudo, as penosas condições em que ele passa a se dar. (Nogueira, 1990, p. 25)

Mas a difusão em larga escala do trabalho infantil foi obra da Revolução Industrial: em 1861 um censo realizado na Inglaterra registrava que quase $37 \%$ dos meninos e $21 \%$ das meninas de 10 a 14 anos trabalhavam, fato também observado em outros países, que também apresentavam taxas altas de crianças trabalhando, como França, Bélgica e Estados Unidos (Kassouf, 2007, [s.p.]). Marx e Engels foram contemporâneos e testemunhas das profundas transformações econômicas e sociais decorrentes da Revolução Industrial e foram fortemente impactados pela situação da criança trabalhadora na grande indústria.

Como não tinham por objeto de análise o trabalho infantil ou a infância, não trataram das formas tradicionais do trabalho infantil. Tal qual outros temas, também a questão da infância não constituiu uma problemática autônoma em Marx ou Engels, mas aparece para realçar a extensão da exploração do trabalho pela moderna indústria capitalista. Sobre o assunto, bem observou Nogueira (Idem, ibidem) que o "tema é sempre apresentado como uma das mais fortes manifestações do modo de exploração do trabalho instaurado pelo capitalismo", quer apareça quando Marx e Engels tratam da evolução da jornada de trabalho, ou do exame da legislação fabril inglesa. É o próprio Marx, no livro primeiro de O Capital, quem forneceu essa chave compreensiva da importância da violência do trabalho infantil como exemplo convincente da exploração do trabalho na moderna indústria

Se, portanto, em nosso esboço histórico desempenha papel importante, de um lado, a moderna indústria e, de outro, o trabalho dos que são física e juridicamente menores, a primeira funcionou apenas como esfera específica, o segundo como exemplo particularmente convincente da exploração do trabalho. (MARX, K.. O Capital - livro 1, volume 1, TOMO 1. 1996, p. 410).

Marx e Engels apontaram uma série de fatores que se combinaram e que levaram ao recrutamento de mulheres e crianças pelo sistema fabril. Em primeiro lugar, o trabalho infantil é tratado em estreita relação com a redução, pelos fabricantes, dos gastos com o pagamento da força de trabalho, uma vez que baixíssimos salários eram pagos às crianças, geralmente não passando da metade ou terça parte do salário pago ao operário adulto (Engels, A situação da Classe Trabalhadora na Inglaterra, 1986). Estabelecia-se um 
circulo vicioso, pelo qual os baixos salários pagos às crianças conduzia à redução do salário do adulto e estes, por sua vez, levavam à necessidade dos pais fazerem seus filhos trabalharem. Com isso o valor da força de trabalho passava a ser determinado pelo tempo de trabalho não só do trabalhador individual, mas de toda a família trabalhadora (do homem, da mulher e das crianças). Foi nesse sentido que Marx observou as consequiências do emprego das mulheres e dos jovens pelo capital:

O valor da força de trabalho era determinado pelo tempo de trabalho não só necessário para a manutenção do trabalhador individual adulto, mas para a manutenção da família do trabalhador. A maquinaria, ao lançar todos os membros da família do trabalhador no mercado de trabalho, reparte o valor da força de trabalho do homem por toda sua família. [...] Agora, quatro precisam fornecer não só trabalho, mas maistrabalho para o capital, para que uma família possa viver. [...]. (Marx, 1996, Tomo 2, p. 28-29).

O emprego de toda família do trabalhador, enquanto uma exigência para a reprodução da força de trabalho, não teria sido possível sem o desenvolvimento da maquinaria, sem a mecanização da produção. Ao estudar o impacto da indústria mecanizada sobre o destino dos trabalhadores, Marx chama a atenção para a capacidade da indústria se apossar de elementos antes à margem do processo produtivo: a mulher e o menor. Na medida em que "a maquinaria torna a força muscular dispensável", pode-se "utilizar trabalhadores sem força muscular ou com desenvolvimento corporal imaturo", com isso "o trabalho de mulheres e de crianças foi a primeira palavra de ordem da aplicação capitalista da maquinaria". (Idem, p. 28). Análise semelhante Engels já havia feito anteriormente, em 1845, relatando que a introdução da máquina não só permitiu como, de certa forma, requereu o trabalho infantil, ao dispensar a força física e demandar agilidade e flexibilidade do trabalhador. Engels sugeriu, outrossim, que razões inseparavelmente técnicas e sócio-econômicas foram responsáveis pelo uso da mão-deobra infantil. Suas observações são lapidares nesse sentido:

\begin{abstract}
Examinemos mais de perto o modo como as máquinas eliminaram cada vez mais o operário adulto. $\mathrm{O}$ trabalho nas máquinas consiste, principalmente, tanto na fiação quanto na tecelagem, em reparar os fios que se rompem, pois a máquina faz o resto. Este trabalho não exige nenhuma força física, mas dedos ágeis. Então, não só os homens não são indispensáveis para isso como, por outro lado, o grande desenvolvimento dos músculos e dos ossos das mãos os tornam menos aptos para este trabalho do que as mulheres e as crianças; por isso, eles são muito natural e quase totalmente afastados deste trabalho. Quanto mais os gestos dos braços, os esforços musculares são, devido à entrada em serviço de máquinas, realizados pela energia hidráulica ou pela força do vapor, menos se necessita de homens. E como de resto as mulheres e as crianças são mais rentáveis e mais háveis que os homens neste tipo de trabalho, são estas que são empregadas. [...] (Engels, 1985, p. 163-164).
\end{abstract}

Apesar da análise econômica ainda estar em seus primeiros passos, Engels era convicto quanto aos motivos que levavam à adoção do trabalho feminino e infantil, apontando que isso não se deu somente porque o desenvolvimento das forças produtivas, com a introdução das máquinas, tornou isso possível, mas porque provocavam a redução do salário, ampliando a exploração: 
[...] Numa família onde todos trabalham, cada membro pode ganhar um pouco menos, e a burguesia aproveitou amplamente a ocasião que lhe foi oferecida pelo trabalho mecânico para utilizar e explorar as mulheres e as crianças tendo em vista a redução dos salários. [...] (Engels, 1985, p. 95)

Engels avançou a análise sobre as consequências sociais do trabalho da mulher e das crianças, baseando-se em vasta quantidade de fontes, relatórios e depoimentos. Analisou detalhadamente como o discurso foi naturalizando, justificando e ideologizando o trabalho de toda a família operária. Somente para ilustração, segue brilhante citação em que registra como a burguesia justificava o trabalho infantil, não perdendo Engels a oportunidade para ironizar o discurso burguês que justificava o emprego das crianças como um ato de filantropia:

Claro, a burguesia diz-nos: "Se não empregarmos as crianças nas fábricas, elas ficarão em condições de vida desfavoráveis ao seu desenvolvimento", e no conjunto este fato é verdadeiro. Mas que significa este argumento, posto no seu justo lugar, senão que a burguesia coloca primeiro os filhos dos operários em más condições de existência e que explora em seguida estas más condições em seu proveito? Ela invoca um fato de que é tão culpada como do sistema industrial, justificando a falta que comete hoje com aquela que cometeu ontem. [...] (Idem. p. 173).

A análise de Engels evidencia que o discurso ideológico da burguesia, tratando o trabalho infantil como expressão de sua própria filantropia, não passava de acobertamento da exploração do trabalho infantil em seu próprio benefício. Para demonstrar sua análise, recorreu aos relatórios dos inspetores de fábrica e ao depoimento de médicos, no quais ficava patente que todos os trabalhadores estavam submetidos a um processo de deformação física e mental que produzia consequencias para toda a vida, principalmente em se tratando do trabalho da mulher e da criança. As justificativas da burguesia não eram suficientes, nem para os inspetores de fábrica, para escamotear "a voracidade dos capitalistas" que, por todos os meios, tinham que "fazer com que o capital investido nas construções e em máquinas fosse rentável” (Idem, p. 174).

\section{A historicidade da utilização da força de trabalho infantil}

Mesmo que Marx e Engels não tenham sistematizado o processo de transformação da utilização do trabalho infantil na produção, buscando entender a infância como uma categoria histórica, com características peculiares e distintas nos diferentes modos de produção e nas diferentes fases do capitalismo, não se pode deixar de registrar, entretanto, que diversas vezes eles assinalaram, de modo bastante claro, as diferenças históricas quanto ao uso do trabalho infantil. Veja-se sobre o assunto, em A situação da classe trabalhadora na Inglaterra, como Engels registrou o emprego das crianças nas fábricas:

[...] Desde o princípio da nova indústria, estas [as crianças] foram empregadas nas fábricas. De início e devido às pequenas dimensões das máquinas (que mais tarde se tornaram mais importantes), eram quase somente as crianças que nelas trabalhavam; iam procurá-las nas casas de assistência, que as alugavam aos industriais como "aprendizes", em grandes grupos e por muitos anos. Eram alojadas e vestidas coletivamente e tornavam-se, bem entendido, escravas dos seus patrões, que as tratavam com uma brutalidade e barbaridade extremas. [...] (Engels, 1985, p.171172) 
$\mathrm{Na}$ imediata sequência Engels registra as repercussões que os abusos patronais contra a infância provocavam na opinião pública, ao final conduzindo à votação da lei sobre os aprendizes, em 1802, pelo parlamento inglês. A aplicação dessa legislação se deu gradativamente, com transformações na indústria: “[...] Pouco a pouco as fábricas foram construídas, sobretudo nas cidades, aperfeiçoando as máquinas e construindo edifícios mais arejados e mais sãos... enquanto se elevou a idade média em que se começava a trabalhar", mas ainda foi necessária intervenção do poder legislativo, "para proteger as crianças contra a rapacidade da burguesia" (Engels, 1985, p. 172).

Engels continua a análise tratando e detalhando as implicações do uso do trabalho infantil: as doenças, a mortalidade infantil, a precária alimentação e descanso, a degeneração física, intelectual e moral imposta às crianças pela burguesia. Também Marx refletiu sobre a "infância da grande indústria", conforme constata-se da longa citação que segue de $O$ Capital, onde registrou que o nascimento desta última [da indústria] é celebrado pelo grande rapto herodiano de crianças.

Apesar de ter tratado dessa questão quando abordei a maquinaria, reforçarei a idéia recorrendo a um texto de Marx que revela minuciosamente a suposta necessidade do trabalho infantil, notadamente detalhando os meios usados para arregimentar essas crianças trabalhadoras, os mal tratos recebidos e a exploração extrema a que estavam submetidas, tratada por Marx em analogia a escravidão. Para fundamentar sua análise, Marx recorre a citação de autores e relatos da época, como os que segue:

"Em Derbyshire, Nottinghamshire e especialmente em Lancashire", diz Fielden, "a maquinaria recentemente inventada foi empregada em grandes fábricas, próximas a correntezas capazes de girar a roda-d'água. Subitamente, milhares de braços tornaram-se necessários nesses lugares, longe das cidades; e Lancashire, a saber até então comparativamente pouco povoado e infértil, necessitava agora, sobretudo, de uma população. Os pequenos e ágeis dedos eram os mais requisitados. Surgiu logo o costume de procurar aprendizes (!) nas diferentes Workhouses paroquiais de Londres, Birmingham e de onde quer que fosse. Muitos, muitos milhares dessas pequenas criaturas desamparadas, de 7 até 13 ou 14 anos, foram assim expedidos para o norte. Era costume do mestre" (isto é, de ladrão de crianças) "vestir, alimentar e alojar seus aprendizes numa casa de aprendizes, próximo à fábrica. Supervisores foram designados para vigiar-lhes o trabalho. Era de interesse desses feitores de escravos fazer as crianças trabalharem ao extremo, pois sua remuneração era proporcional ao quantum de produto que podia ser extraído da criança. Crueldade foi a conseqüência natural. (...) (apud Marx, 1996, Tomo 2, pp. 376-377)

Marx ilustrou ainda mais estes fatos, em uma nota de rodapé, citando exemplos mencionados por F. Horner, em depoimento perante a Câmara dos Comuns, onde afirmava:

"É notório que junto com a massa falida, um bando, se me permitem essa expressão, de crianças de fábrica foi anunciado e arrematado, em leilão público, como parte da propriedade. Há dois anos" (em 1813) "chegou perante a King's Bench um caso horroroso. Tratava-se de certo número de garotos. Uma paróquia de Londres tinha-os consignado a um fabricante, que os transferiu de novo a outro. Eles foram finalmente 
descobertos por alguns filantropos, num estado de completa inanição (absolute famine). Outro caso, ainda mais horroroso, chegou a meu conhecimento como membro do comitê parlamentar de inquérito. Há não muitos anos, uma paróquia londrina e um fabricante de Lancashire concluíram um contrato, pelo qual foi estipulado que este, para cada 20 crianças sadias, teria de aceitar uma idiota".[Marx iniciou a nota registrando que] Visto que a máquina a vapor transplantou as fábricas das quedas-d'águas rurais para o centro das cidades, o extrator de mais-valia, sempre "pronto à renúncia", encontrou à mão o material infantil, sem a oferta forçada de escravos das Workhouses. (Idem, p. 377, nota de rodapé 766 )

Certamente Marx e Engels não produziram uma análise teórica minuciosa do uso do trabalho infantil pela nascente indústria inglesa, mas as passagens citadas são suficientemente esclarecedoras da visão que tinham da trajetória historicamente percorrida pelo uso da força de trabalho infantil na Inglaterra. Maria Alice Nogueira, em seu Educação, saber, produção em Marx e Engels, entende que Marx e Engels abordam o uso do trabalhado infantil em dois momentos, desvelados pela forma de agenciamento das crianças:

[...] nos primórdios da indústria, recorreu-se sobretudo às crianças atendidas pela assistência paroquial, chamadas de "aprendizes" (órfãos, abandonados, indigentes etc.). As paróquias, mediante acordos feitos com os fabricantes, comprometiam-se a fornecer-lhes certo contingente de crianças aptas ao trabalho; e isto em razão da dificuldade de se encontrar mão-de-obra infantil disponível na zona rural onde se procurava instalar as manufaturas, à proximidade de quedas-d'água, uma vez que a força hidráulica era a energia mais utilizada nesse primeiro momento.

Gradualmente, no entanto, com a preferência dada à máquina a vapor em relação à energia hidráulica, as usinas começaram a se implantar cada vez mais nas cidades onde uma mão-de-obra abundante, constituída de mulheres e de crianças, passou a ser requisitada. É nesse sentido [...] que Marx afirma que, a partir desse momento, o industrial pôde dispensar as workhouses como fonte principal de abastecimento. Agora, a mercadoria força de trabalho infantil será diretamente fornecida ao fabricante, pelo pai de família... (Nogueira, 1990, p. 34-35)

Como não era o trabalhador que vendia sua própria força de trabalho, como uma pessoa formalmente livre, era uma situação análoga ao trabalho escravo. Estando o fabricante na condição de "proprietário virtual da criança", julgava ter vastos poderes sobre as condições de vida e de trabalho das crianças, levando "aos maus-tratos e à sobrecarga de trabalho" (Idem, p. 35). Isso levou ao estabelecimento de limitações legais impostas pelo Estado, na primeira parte do século XIX, quando o uso do menor pelos capitalistas foi normatizado e submetido a restrições legais, como já apontei.

Para melhor e mais amplamente entender como, historicamente, se deu a utilização da força de trabalho infantil, Nogueira sistematizou a contribuição de vários autores4, notadamente D.S. Landes e sua obra L'Europe technicienne ou le Prométhée libere. Fazendo uma relação entre os fatores técnicos da produção e as transformações no recrutamento da criança, formula três grandes momentos, ou três etapas, quanto ao uso do trabalho infantil. 
waterframe -, quando o apelo à força de trabalho de mulheres e crianças era ainda reduzido (por ser a jenny uma máquina movida a mão através de uma manívela), recrutou-se essencialmente as crianças da assistência social. Com a invenção da mule-jenny, que mecaniza o trabalho de fiação, a demanda de mão-de-obra infantil cresce fortemente e as crianças das workhouses já não são mais suficientes; os empresários passam, então, a recorrer prioritariamente à família operária: mulheres e filhos dos trabalhadores serão recrutados em larga escala. Finalmente, a introdução do self-actor (bobinadeira automática), que desenvolve o movimento automático das máquinas de fiar, vai se associar as restrições à utilização dos pequenos trabalhadores impostas por intervenção do poder estatal, através das "leis de fábrica". Nesse último estádio, conforme Landes, já poderíamos falar de integração ao sistema fabril, pois que "uma nova geração já havia crescido em meio à disciplina e ao rigor da fábrica". (Nogueira, 1990, p. 36-37)

Face as referidas péssimas condições de vida e de trabalho das crianças, no decorrer do século XIX, foi marcante o processo, por parte dos poderes legislativos e executivos de diferentes países, de regulamentação do uso da mão-de-obra infantil, em nome de supostos "direitos da criança". De modo geral, qualquer que fosse o país, as leis regulamentadoras do trabalho infantil repousavam geralmente sobre três pontos principais: a) regulamentação da idade mínima de admissão ao trabalho, b) estabelecimento da duração da jornada de trabalho; c) imposição de uma freqüência escolar mínima obrigatória para as crianças de fábrica (Nogueira, 1990, p. 40-41). Face a tais evidencias, não posso deixar de registrar que o capital não estava preocupado em salvar a criança dos maus tratos, mas que precisou socorrer sua "galinha de ovos de ouro", senão não haveria mão-de-obra trabalhadora a ser usada no futuro.

\section{Considerações Finais}

As observações feitas sobre o entendimento de Marx e Engels possibilita suficiente entendimento sobre como tratavam os autores a questão. Mesmo que continuasse a fazer referências e citações das obras, foi esse o panorama traçado por Marx e Engels quanto à situação educacional da criança trabalhadora durante a Primeira Revolução Industrial. Certamente esses autores não objetivaram fazer uma análise exaustiva dessa questão, contudo o quadro geral que traçaram sobre as condições de vida dos trabalhadores é suficientemente claro quanto a precária formação e instrução recebida pelos trabalhadores, apesar do aparecimento de algumas formas escolares que buscavam contornar a quase inexistente estrutura escolar destinada à infância operária, como as escolas de fábrica, do "meio-dia", do domingo, os cursos noturnos, o ensino mútuo etc.

Aspecto fundamental a destacar é que os dois autores, mesmo estando em diferentes momentos de produção da obra, tinham o entendimento das condições de instrução dos trabalhadores a partir do contexto histórico, no interior do qual se produziam as próprias condições de vida e de trabalho. É impossível entender a problemática educacional em si mesma, pois metodológica e teoricamente é o contexto e suas determinantes econômicas, sociais, políticas, etc. que fornece a chave explicativa do conteúdo e da forma que a educação assumiu (e assume) na história das mais diferentes formações sociais e econômicas. Penso que as formulações de Marx e Engels sobre educação e ensino sempre aparecem coladas às observações e análises que fazem sobre as condições de vida e trabalho das classes sociais, particularmente da classe trabalhadora. Não estavam preocupados em elaborar teorias gerais e abstratas sobre os aspectos e dimensões da vida social que estudavam, ao contrário, analisando as condições de vida e 
de trabalho do proletariado de então é que acabaram formulando a necessária união da instrução com o trabalho material.

No meu entendimento, a fábrica e a escola analisada pelos autores foi a base e o ponto de partida para pensarem o que seria a educação do futuro... de uma educação que contribuísse para a construção de um novo homem e de uma nova sociedade. Foi certamente a análise da situação de instrução das crianças trabalhadoras de então que os levaram à defesa, no âmbito dos debates da Associação Internacional dos Trabalhadores, de uma escola pública, obrigatória, gratuíta e laica. Para além desta, a união indissociável da educação com o trabalho, mas com a superação de um ensino (mono)técnico por uma educação politécnica e que buscasse construir o homem em sua totalidade.

\section{Bibliografia}

ARCE, Alessandra. A pedagogia na "Era das Revoluções". Campinas, SP : Autores Associados, 2002.

ARIÈS, P. História social da criança e da família. 2ª Ed.. Rio de Janeiro : Zahar, 1981.

BOTTOMORE, Tom (editor) e outros. Dicionário do Pensamento Marxista. Rio de Janeiro : Jorge Zahar Editor, 1988.

ENGELS, F.. A Situação da Classe Trabalhadora na Inglaterra. São Paulo : Global, 1985.

FREITAS, M.C. de e KUHLMANN JR., Moysés (orgs.). Os intelectuais na história da infância. São Paulo : Cortez, 2002.

FREITAS, Marcos Cezar de (org.). História social da infância no Brasil. São Paulo : Cortez, 1997.

KASSOUF, Ana Lúcia. O que conhecemos sobre o trabalho infantil?. Nova

Economia. vol.17 no.2 Belo Horizonte May/Aug. 2007. Versão eletrônica disponível em: http://www.scielo.br/scielo.php?script=sci_arttext\&pid=S0103-

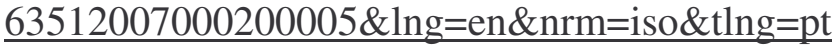

KUHLMANN JR., Moysés. Infância e educação infantil. Porto Alegre : Mediação, 1998.

MARX e Engels. A Ideologia Alemã: crítica da filosofia alemã mais recente na pessoa dos seus representantes Feuerbach, B. Bauer e Stirnes, e do socialismo alemão na dos seus diferentes profetas. Volume I e II. Lisboa : Editorial Presença; Brasil : Livraria Martins Fontes. [s.d.]

MARX, K.. "Crítica ao Programa de Gotha". In: MARX, K. e F. Engels. Obras Escolhidas - Volume 2. São Paulo : Alfa-Omega, s/d., p. 203-225.

MARX, Karl e F. Engels. Obras Escolhidas - Volume 1. São Paulo : Alfa-Omega, s/d.

MARX, Karl e F. Engels. Obras Escolhidas - Volume 2. São Paulo : Alfa-Omega, s/d.

MARX, Karl e F. Engels. Obras Escolhidas - Volume 3. São Paulo : Alfa-Omega, s/d.

MARX, Karl. Instruções para os Delegados do Conselho Geral Provisório.

As Diferentes Questões. Agosto de 1866. Texto eletrônico disponível em:

[http://www.marxists.org/portugues/marx/1866/08/instrucoes.htm].

MARX, Karl. O capital. Crítica da Economia Política. Livro Primeiro. VOLUME I. O Processo de Produção do Capital. TOMO 1 (Prefácios e Capítulos I a XII). São Paulo : Editora Nova Cultural, 1996. (Os Economistas). 
MARX, Karl. O capital. Crítica da Economia Política. Livro Primeiro. VOLUME I. O Processo de Produção do Capital. TOMO 2 (Capítulos XIII a XXV). São Paulo : Editora Nova Cultural, 1996. (Os Economistas).

NOGUEIRA, Maria Alice. Educação, saber, produção em Marx e Engels. São Paulo : Cortez : Autores Associados, 1990.

NOSELLA, Paolo. A linha vermelha do planeta infância: o socialismo e a educação da criança. In: FREITAS, M.C. de e KUHLMANN JR., Moysés (orgs.). Os intelectuais na história da infância. São Paulo : Cortez, 2002, p. 129-166.

Notas:

${ }^{1}$ Professor livre-docente do Departamento de Filosofia e História da Educação da Unicamp. Coordenador executivo do HISTEDBR. Pesquisador bolsista do CNPq.

${ }^{2}$ As informaçãos que seguem constam do site da UNICEF em http://www.childinfo.org/labour.html

${ }^{3}$ O SITI encontra-se no seguinte endereço eletrônico: http://siti.mte.gov.br/focuses/list

${ }^{4}$ Para registro e consulta, Nogueira referencia as obras dos seguintes autores:

D. LANDES, L'Europe technicienne ou le Prométhée libéré - révolution technique et libre essor industriel en Europe occidentale de 1750 à nos jours. Paris, Gallimard, 1975.

SANDRIN, Enfants trouvés, en/ants ouvriers - XVJP-X1X siècle. s 1., Aubier, 1982.

DOUAILLER e P. VERMEREN, Les enfants du capital: de l'hospice à la manufacture, in Les Révoltes Logiques, Paris, n. ${ }^{0}$ 3, 1976, p. 9.

R. BIED e R. PONTHUS, Le travail des enfants au XJX siècle. Sercice Educatif des Archives

Departamentales et Centre Départamental de la Documentation Pédagogique du Vai-de-Mame, 1982

Artigo recebido em: 16/11/10

Aprovado em: 30/11/10 